\title{
Pagamento por serviços ambientais por desmatamento evitado: proposta de estimação do custo de oportunidade do uso do solo para pecuária no Mato Grosso
}

O mecanismo de redução de emissões provenientes do desmatamento e degradação florestal (REDD) foi um tema que ganhou mais relevância a partir da Conferência das Nações Unidas sobre Mudança Climática (COP 13), realizada em 2007 em Bali. A partir de então, este se tornou o tema central das negociações entre as partes, que chegaram a um acordo sobre o REDD+ em 2010 realizado em Cancun (COP 16), onde o REDD passou a envolver a conservação, a administração sustentável de florestas e o aumento do estoque de carbono. A ideia básica do REDD é recompensar financeiramente os países dispostos e em condições de reduzir as emissões por desmatamento. Cogita-se que sistemas estaduais estejam considerando outras opções para o financiamento de suas ações de REDD+ pelo uso de incentivos positivos como tributos e pagamentos por serviços ambientais (PSAs). No caso do Estado do Mato Grosso com altas taxas de desmatamento induzidas, sobretudo, pela expansão da pecuária, a implementação de esquemas de PSAs como mecanismos financeiros para incentivar a redução de emissões de carbono por desmatamento surge como uma possibilidade de reverter esse quadro. Nesse sentido, o objetivo geral deste trabalho é estimar o custo do carbono suficiente para compensar o custo de oportunidade do uso da terra em regiões onde ocorre uma grande perda dos benefícios dos serviços ambientais devido ao desmatamento. O objetivo específico é investigar se os níveis de preço da tonelada de carbono em termos de rentabilidade compensam a preservação da floresta do ponto de vista privado em caso de implementação de PSA na região. Esta estimativa toma por base o cenário recente da pecuária no estado do Mato Grosso, assim, é pertinente o levantamento da rentabilidade desta atividade como uma proxy do custo de oportunidade do uso da terra associado as emissões de carbono pelo desmatamento.

Palavras-chave: Desmatamento; Pagamento por serviços ambientais; Expansão da pecuária.

\section{Payment for environmental services for avoided deforestation: proposal for estimating the cost of opportunity for land use for livestock in Mato Grosso}

\begin{abstract}
The mechanism for reduction emission from deforestation and forest degradation (REDD) was a topic that has gained more relevance from the United Nations Conference on Climate Change (COP 13) held in 2007 in Bali. Since then, this has become the main focus of negotiations between the parties, which reached an agreement on REDD + in 2010 held in Cancun (COP 16), where the REDD began to involve conservation, sustainable management of forests and increasing carbon storage. The basic idea of REDD is financially reward those willing and able to reduce emissions from deforestation countries. It is thought that state systems are considering other options for financing their REDD + actions through the use of positive incentives such as taxes and payments for environmental services (PES). In the case of Mato Grosso state with high rates of deforestation induced mainly by the expansion of livestock, the implementation of PES schemes as financial mechanisms to encourage the reduction of deforestation carbon emissions comes as an opportunity to reverse this situation. Accordingly, the aim of this study is to schemes as financial mechanisms to encourage the reduction of deforestation carbon emissions comes as an opportunity to reverse this situation. Accordingly, the aim of this study is to
estimate the cost of enough carbon to offset the opportunity cost of land use in areas where there is a large loss of the benefits of ecosystem services due to deforestation. The specific objective is to investigate whether the ton of carbon price levels in terms of profitability outweigh the preservation of the private point of view forest in case of implementation of PES in the region. This estimate is based on the recent scene of cattle in the state of Mato Grosso is thus relevant lifting the profitability of this activity as a proxy for the opportunity cost of land use associated carbon emissions from deforestation.
\end{abstract}

Keywords: Deforestation; Payment for environmental services; Expansion of livestock.

Topic: Valoração e Economia Ambiental

Reviewed anonymously in the process of blind peer.
Received: 03/02/2021

Approved: 26/02/2021
Vanessa da Paixão Alves

Universidade Federal do Pará, Brasil

http://lattes.cnpq.br/3594057948991124

vass321@hotmail.com

Abner Vilhena de Carvalho (iD

Universidade Federal do Oeste do Pará, Brasil

http://lattes.cnpq.br/8971980101556291

http://orcid.org/0000-0003-3501-6611

abnervilhena@hotmail.com

Jarsen Luis Castro Guimarães

Universidade Federal do Oeste do Pará, Brasi

http://lattes.cnpq.br/2403664119078137

jarsen.guimaraes@ufopa.edu.br
Juarez Bezerra Galvão

Universidade Federal do Oeste do Pará, Brasil http://lattes.cnpq.br/9436222631929060 juarez.galvao@ufopa.edu.br

\section{Mario Tanaka Filho}

Universidade Federal do Oeste do Pará, Brasil

http://lattes.cnpq.br/5710278151289710

mario.filho@ufopa.edu.br

Ednéa do Nascimento Carvalho

Universidade Federal do Oeste do Pará, Brasil

http://lattes.cnpq.br/7125890853681726

ednea.carvalho@ufopa.edu.br

\section{Rodolfo Maduro Almeida \\ Universidade Federal do Oeste do Pará, Brasil http://lattes.cnpq.br/1527651015984510} rodolfo.almeida@ufopa.edu.br

\section{João Roberto Pinto Feitosa}

Universidade Federal do Oeste do Pará, Brasil http://lattes.cnpq.br/7036507992139090 joao.feitosa@ufopa.edu.br
Referencing this:

ALVES, V. P.; CARVALHO, A. V.; GUIMARÃES, J. L. C.; GALVÃO, J. B. G.; TANAKA FILHO, M.; CARVALHO E. N.; ALMEIDA, R. M.; FEITOSA, J. R. P.. Pagamento por serviços ambientais por desmatamento evitado: proposta de estimação do custo de oportunidade do uso do solo para pecuária no Mato Grosso. Revista Ibero Americana de Ciências Ambientais, v.12, n.2, p.699-714, 2021. DOI:

http://doi.org/10.6008/CBPC2179-6858.2021.002.0058 
Pagamento por serviços ambientais por desmatamento evitado: proposta de estimação do custo de oportunidade do uso do solo para pecuária no Mato Grosso

ALVES, V. P.; CARVALHO, A. V.; GUIMARÃES, J. L. C.; GALVÃO, J. B. G.; TANAKA FILHO, M.; CARVALHO E. N.; ALMEIDA, R. M.; FEITOSA, J. R. P.

\section{INTRODUÇÃO}

As políticas de incentivo fiscais do governo entre as décadas de 60 e 80 contribuíram para a expansão da pecuária na Amazônia. Neste período a pecuária tornou-se uma atividade expressiva usada como um instrumento de ocupação territorial que nasce das estratégias intervencionistas de desenvolvimento regional criadas pelo Estado no contexto do planejamento nacional, onde havia o intuito de modernização do setor produtivo do país através da substituição de importações. Para tanto, o capital monopolista (externo e interno) tornou-se a base dos recursos usados pelo Estado para promover essa modernização (SILVA, 2010). Em um primeiro momento a Amazônia será inserida neste contexto e planejamento a nível regional, mas devido à desigualdade de formação econômica brasileira. Assim, a política de modernização, a nível nacional, vai se concentrar nos setores os quais havia uma pré-disposição para a modernização (atividades agrícolas localizadas no Centro-sul).

Em termos de um aspecto geopolítico norteador das políticas regionais nesse período, havia a intenção de ocupação regional e, nesse sentido, a pecuária era uma das atividades prioritárias do governo. De acordo com Silva (1982, citado por SILVA, 2010), a "atividade pecuária pode ser interpretada como uma expressão histórica de ocupação da fronteira", visto que, a ocupação das terras na Amazônia funcionava como uma garantia de reserva de valor anterior ao processo de produção com a finalidade precípua da posse da propriedade privada da terra. Quanto a isso, a derrubada e queimada da mata para a formação da pastagem e posterior ocupação de bovinos propiciava uma rápida e eficiente forma de posse da terra (RIVERO et al., 2008). Esses aspectos serviram de justificativa para o acesso a estímulos governamentais, tais como incentivos fiscais e creditícios subsidiados, que impulsionaram a propagação da bovinocultura na região. $O$ principal instrumento de incentivo à atividade foi a Lei no 5.174 , de 1966, a qual garantia às pessoas jurídicas brasileiras o desconto de até $5 \%$ do imposto de renda devido desde que seus investimentos se destinassem a projetos na Amazônia Legal e aprovados pela Sudam.

Dos investimentos projetados para o setor pecuário, cerca de $90 \%$ do total concentravam- se nos estados do Mato Grosso e do Pará, tendo o primeiro mais de $60 \%$ desses investimentos. Além das vantagens obtidas com a existência de terras baratas e abundantes havia a clara a preferência locacional dos proprietários de projetos pecuários por terras próximas aos novos sistemas rodoviários inter-regionais (rodovias Belém-Brasília, Transamazônica e Santarém-Cuiabá). Por conta disso, a partir da década de 1980 o que se observa é um deslocamento da pecuária das regiões Sul e Sudeste para a região amazônica.

Nos anos recentes, a pecuária bovina é a forma de uso do solo mais importante em todos os estados da Amazônia, sendo responsável pelo aumento do desmatamento nos anos 2000. Essa atividade, em geral, apresenta crescimento em todos esses estados, tornando a criação de gado a atividade econômica de maior impacto em toda a região (BARRETO et al., 2005). Essa nova dinâmica do desmatamento representa, consequentemente, maior emissão de gases de efeito estufa, uma vez que, o carbono existente no ecossistema de pastagem, após dez anos de uso, é de apenas $10 \%$ do encontrado na floresta original. Assim, cerca de 160 toneladas de carbono são liberadas para a atmosfera quando há conversão de florestas em 
Pagamento por serviços ambientais por desmatamento evitado: proposta de estimação do custo de oportunidade do uso do solo para pecuária no Mato Grosso

ALVES, V. P.; CARVALHO, A. V.; GUIMARÃES, J. L. C.; GALVÃO, J. B. G.; TANAKA FILHO, M.; CARVALHO E. N.; ALMEIDA, R. M.; FEITOSA, J. R. P.

pastagens, contribuindo para o aquecimento global e possíveis efeitos sobre a biodiversidade regional (UHL et al., 1997).

Nesse sentido, a partir da revisão bibliográfica sobre a dinâmica de uso do solo na região do levantamento de dados sobre a rentabilidade da pecuária bovina no estado do Mato Grosso, este artigo tem por objetivo estimar o custo de oportunidade do uso da terra associado às emissões de carbono pelo desmatamento provocado, sobretudo, pela expansão da pecuária. Através do princípio do custo de oportunidade assume-se a hipótese de que alternativas de preservação ambiental geram benefícios que são pelo menos iguais aos benefícios (rendas) renunciados. Esta inferência é fundamental para dar suporte às ações de REDD+ que visam a mitigação o desmatamento.

Além desta introdução, este artigo encontra-se dividido em 5 seções. A segunda seção trata da dinâmica do desmatamento na Amazônia, enfatizando a papel do Estado do Mato Grosso nesse processo, a terceira seção discorre a respeito do REDD e dos programas de Pagamentos por Serviços Ambientais, a quarta seção trata do referencial teórico, descreve os procedimentos metodológicos e os resultados alcançados com a pesquisa e por fim, a quinta e última seção faz as considerações finais sobre a pesquisa aqui desenvolvida.

\section{METODOLOGIA}

\section{Dinâmica do desmatamento a partir do uso do solo na Amazônia}

Segundo os dados do projeto TerraClass da Embrapa e INPE gerados com base na área de desflorestamento do projeto PRODES ${ }^{1}$ (Projeto de Mapeamento de Desflorestamento), para o ano de 2008, a área da Amazônia Legal destinada à pecuária bovina já chegava a 44,7 milhões de hectares, atingindo em 2010 o valor de 45,9 milhões de hectares (INPE, 2013). Desse modo, os resultados do mapeamento do TerraClass para o ano de 2010 indicam que as áreas de pastagens continuam com o maior percentual nas áreas desflorestadas e incluem as classes: pasto limpo, pasto sujo, regeneração com pasto e pasto com o solo exposto, ocupando $66 \%$ do total das áreas desflorestadas. A agricultura anual ${ }^{24}$ é responsável por 5,4\% do total de áreas desflorestadas (cerca de 4 milhões de hectares). Os gráficos 1 a seguir resume os resultados referentes às frequências relativas dos diferentes usos e coberturas da terra nos desflorestamentos para o ano de 2009.

Os resultados do projeto também apontam para um aumento das áreas de vegetação secundária (áreas desflorestadas previamente que estão em fase de regeneração) de cerca de 22\% (16,6 milhões de hectares) em 2010, diferente dos 21\% (15 milhões hectares) do total das áreas desflorestadas até 2008.

O desmatamento na Amazônia brasileira aumentou continuamente desde 1991 devido a vários fatores econômicas. As mudanças observadas nas últimas duas décadas incluem um pico no desmatamento em 1995, resultado do Plano Real, e uma queda em 2005, resultado de taxas de câmbio desfavoráveis para

\footnotetext{
${ }^{1}$ Segundo informações do PRODES, havia $3.198 .782,70 \mathrm{Km}^{2}$ de floresta (78,8\%); 739.672,54 Km² de desflorestamento acumulado até o ano de 2009 $(18,2 \%) ; 6.714,93 \mathrm{Km}^{2}$ de desflorestamento para o ano de $2010(0,2 \%)$ e $114.914,37 \mathrm{Km}^{2}$ de hidrografia $(2,8 \%)$.

2 “Áreas extensas com predomínio de culturas de ciclo anual, sobretudo de grãos, com emprego de padrões tecnológicos elevados, tais como uso de sementes certificadas, insumos, defensivos e mecanização, entre outros" (INPE, 2013).
} 
Pagamento por serviços ambientais por desmatamento evitado: proposta de estimação do custo de oportunidade do uso do solo para pecuária no Mato Grosso

ALVES, V. P.; CARVALHO, A. V.; GUIMARÃES, J. L. C.; GALVÃO, J. B. G.; TANAKA FILHO, M.; CARVALHO E. N.; ALMEIDA, R. M.; FEITOSA, J. R. P.

exportações, combinado com a "operação Curupira" para conter a exploração de madeira ilegal em Mato Grosso, junto com a criação de reservas e uma área interditada no Pará após o assassinato de Dorothy Stang (FEARNSIDE, 2006).

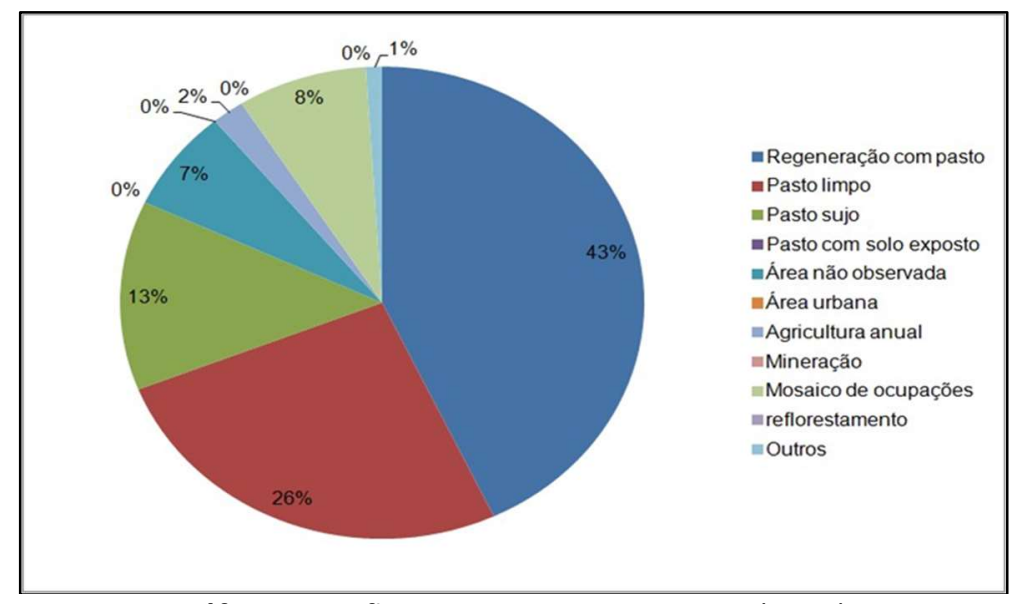

Gráfico 1: Desflorestamento. Fonte: INPE (2013).

O aumento do desmatamento observado no final de 2007, associado ao aumento dos preços do gado e da soja, levou o governo a intensificar as medidas como intuito de reduzir o desmatamento, entre elas estavam: o embargo de licenciamento de desmatamentos em 36 municípios com maior área desmatada e com maiores taxas de desmatamento recentes (Decreto no 6.321/07); o embargo de áreas ilegalmente desmatadas, podendo haver sanções a compradores de produtos oriundos dessas áreas como frigoríficos, madeireiras e processadoras de grãos (Instrução Normativa no 01/2008 do MMA); e a campanha de fiscalização "Operação Arco de Fogo" apreendeu bens em algumas localidades, como 23 mil metros cúbicos de tora em Tailândia, no leste do Pará, e 3.046 cabeças de gado na Estação Ecológica da Terra do Meio, no Pará (este gado foi leiloado em agosto de 2008), entre outras medidas. Estas medidas demonstram ter sido eficazes, uma vez que, o desmatamento apresentou queda de $6 \%$ no período de agosto de 2007 a julho de 2008, e a maior queda (71\%) foi observada em julho de 2008 (BARRETO et al., 2008).

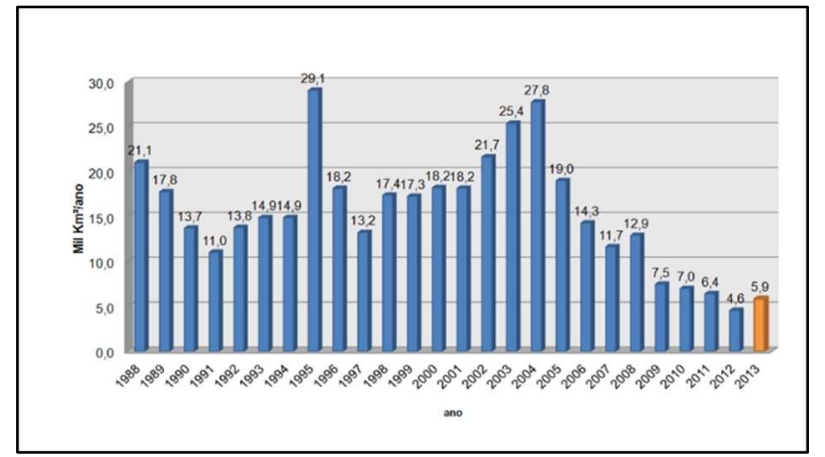

Gráfico 2: Taxa de Desmatamento Anual na Amazônia Legal. Fonte: INPE/Prodes $(2013)^{3}$.

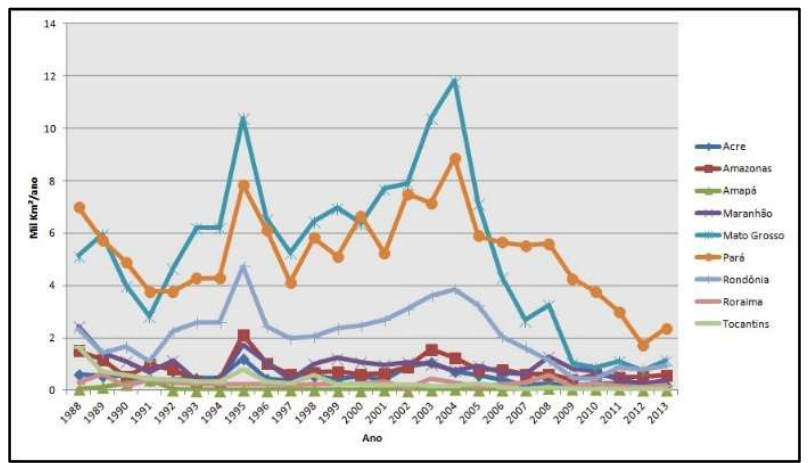

Gráfico 3: Taxa de Desmatamento Anual nos estados da Amazônia Legal. Fonte: INPE/Prodes (2013)

Sobre as taxas de desmatamento nos anos 2000, os dados detalhados pelo Instituto Nacional de 
Pagamento por serviços ambientais por desmatamento evitado: proposta de estimação do custo de oportunidade do uso do solo para pecuária no Mato Grosso

ALVES, V. P.; CARVALHO, A. V.; GUIMARÃES, J. L. C.; GALVÃO, J. B. G.; TANAKA FILHO, M.; CARVALHO E. N.; ALMEIDA, R. M.; FEITOSA, J. R. P.

Pesquisas Espaciais (INPE) apontam uma média das estimativas das taxas anuais de desmatamento na Amazônia no período de 2000 a 2012 de $14.970 \mathrm{Km}^{2}$ (INPE, 2013). Contudo, o desmatamento teve queda significativa entre 2006 e 2012, com uma média de 9,2 mil km². Em 2012 registrou-se a menor taxa de desmatamento na Amazônia: 4,7 mil Km² (SANTOS et al., 2013), porém, em 2013, o desmatamento voltou a subir apresentando uma taxa de 5,8 mil Km², dessa forma, houve uma interrupção da tendência de queda observada desde 2009 (Gráfico 2) (INPE, 2013). Entre os Estados da Amazônia Legal o desmatamento ocorre principalmente no Pará (41\%), Mato Grosso (20\%) e Rondônia (16\%) (Gráfico 3).

Nota-se que na região as atividades que mais desmatam são aquelas relacionadas com a pecuária, à soja e as madeireiras (MARQUES, 2010). Acerca dos municípios situados nas novas fronteiras de desmatamento e ocupação, observa-se que a exploração de madeira predatória e a pecuária extensiva são as principais atividades econômicas presentes na região (CELENTANO et al., 2007). Acerca da extensão das propriedades, a parte norte do Mato Grosso e muito das partes sul e leste do Pará são predominantemente ocupadas por grandes fazendas de pecuária. Em regiões do Pará como em Novo Repartimento, onde há focos de desmatamento, os pequenos agricultores apresentam-se como os principais agentes de devastação. Assim como em Rondônia e ao longo da rodovia Transamazônica no Pará e no Amazonas. No entanto, regionalmente, o que impera são as fazendas grandes e médias (MARGULIS, 2003; FEARNSIDE, 2006).

Os anúncios de projetos de construção e melhoria de rodovias, tais como a reconstrução das rodovias BR-163 (Cuiabá-Santarém) e a BR-319 (Manaus-Porto Velho), leva a uma corrida especulativa da posse de terra, com "grileiros" que esperam lucrar com o rápido aumento do preço da terra assim que as obras das rodovias estejam concluídas. Logo, o crescimento continuo de obras de infraestrutura de transporte representa uma perspectiva de níveis mais altos de desmatamento futuro. Aliado a esses fatores, a atividade pecuária de corte na Amazônia Oriental $\left.\right|^{5}$ apresenta taxas de retorno, acima de 10\%, superiores às da pecuária nas regiões tradicionais do país. Nesse sentido, a redução da perda de floresta representa uma oportunidade, haja vista que, a maior parte do desmatamento é provocada por pastagens pouco produtivas, desse modo, uma redução significativa na taxa de desmatamento representaria um custo de oportunidade pequeno para a economia nacional (FEARNSIDE, 2006).

Nesse sentido, existe uma percepção equivocada, no que se refere aos agentes responsáveis pelo desmatamento, na avaliação dos benefícios econômicos e sociais do processo, implicando em falhas nas políticas públicas voltadas para a região. Durante algum tempo se disseminou a crença da existência de uma correlação positiva muito forte entre pobreza e destruição ambiental, portanto, a solução para a redução da pressão sobre a floresta seria afastar os "pobres" do acesso a ela. No entanto, como afirma Wunder (2001, citado por RIVERO et al., 2008), está visão é simplista e estática. Segundo o autor, existe uma pobreza histórica que não tem relação direta com a dinâmica atual de destruição da floresta e a pobreza que combinada a outros fatores como o crescimento populacional e a apropriação de terras contribuem para o auto reforço da degradação florestal. Enfim, com base nisso, as políticas públicas com intuito de mitigação

${ }^{5}$ Amazônia Oriental comporta os estados do Pará, Rondônia, Mato Grosso, Tocantins e Amapá. 
Pagamento por serviços ambientais por desmatamento evitado: proposta de estimação do custo de oportunidade do uso do solo para pecuária no Mato Grosso

ALVES, V. P.; CARVALHO, A. V.; GUIMARÃES, J. L. C.; GALVÃO, J. B. G.; TANAKA FILHO, M.; CARVALHO E. N.; ALMEIDA, R. M.; FEITOSA, J. R. P.

do impacto ambiental/desmatamento na Amazônia, principalmente nas sub-regiões que mais contribuem para esse problema, devem reconhecer a existência de trade-offs no processo de desmatamento quanto à avaliação sobre os custos e benefícios sociais proporcionadas pelas atividades econômicas como a pecuária extensiva.

\section{RESULTADOS E DISCUSSÃO}

\section{A atividade pecuária: histórico, tendências e impactos ambientais}

Segundo Mahar (1978, citado por SILVA, 2010), existem três modelos de pecuária praticados na Amazônia, dois modelos anteriores aos projetos da Sudam que são: (i) primeiro modelo denominado de "superextensivo tradicional" presente nos estados do Amapá, do Roraima, do Amazonas e no nordeste do Pará, praticado em áreas desfavoráveis à pecuária, mas que era incentivado pela demanda dos mercados de Belém e Manaus, (ii) segundo modelo, "extensivo tradicional", praticado nos estados do Acre, de Rondônia, centro e norte do Pará, e partes do nordeste de Mato Grosso e Goiás, regiões mais propicias a formação de pastagens artificiais e a criação do gado, e (iii) modelo "extensivo modernizador", o qual recaiu a maior parte dos projetos da Sudam, é adotado em fazendas localizadas em geral no leste e sudeste do Pará, norte de Mato Grosso e Goiás, e oeste do Maranhão (Imperatriz). Estas regiões tendem a especializar-se na produção de carne e usam tipos de gados (raças indianas, principalmente Gir e Nelore) muito superiores aos outros dois primeiros modelos citados.

Marie-Gabrielle et al. (2004) aponta três fatores que contribuíram para que na Amazônia Oriental se configurasse como um ambiente favorável a expansão da pecuária, especialmente no Pará e no Mato Grosso: (i) eficiência e adaptação do sistema forrageiro baseado na pastagem Brachiaria brizantha, vulgarmente chamada de "braquiarão". Esse tipo de pastagem possui uma adaptação singular às características extensivas da pecuária da região; (ii) existência de financiamentos públicos, nas décadas de 1970 e 1980, em particular via sistema Finam/Sudam e, a partir da década de 1990, por recursos disponibilizados pelo Fundo Constitucional do Norte (FNO) do Basa; e (iii) a experiência agropecuária do produtor que acredita na atividade para quebrar o ciclo da pobreza.

Sobre o investimento estatal através dos incentivos fiscais via Sudam e Basa, Marques (2010) afirma que esses foram constantes até o início dos anos 1990 quando se observa uma queda desses incentivos e a busca da grande produção agropecuária por outras fontes de financiamento. Uma tendência que foi marcada pelo maior investimento do BDNES em frigoríficos brasileiros, visando transformar o Brasil em campeão mundial de exportação de carne bovina. Em prol desses estímulos ao crescimento dos grandes frigoríficos nacionais, em 2008, o banco destinou metade do total de crédito industrial para às indústrias frigoríficas, cujas instalações apresentavam grande expansão nos estados do Pará e do Mato Grosso.

O gado produzido na Amazônia é comercializado vivo ou como carne (em 2006, o boi vivo e a carne somaram $10 \%$ do total da produção da região exportada para o exterior). Entre 2000 e 2006, o estado do Mato Grosso foi o principal exportador, tendo maior peso no crescimento das exportações da região, isso se 
Pagamento por serviços ambientais por desmatamento evitado: proposta de estimação do custo de oportunidade do uso do solo para pecuária no Mato Grosso

ALVES, V. P.; CARVALHO, A. V.; GUIMARÃES, J. L. C.; GALVÃO, J. B. G.; TANAKA FILHO, M.; CARVALHO E. N.; ALMEIDA, R. M.; FEITOSA, J. R. P.

deveu a um maior controle da febre aftosa nos principais polos produtores. Nesse período, os principais importadores de carne foram os europeus e sul-americanos, que consumiram respectivamente $54 \%$ e $35 \%$ do volume total de carne exportado, a União Europeia comprou $48 \%$ do volume total exportado (BARRETO et al., 2008).

Com base nos dados do Anualpec ${ }^{6}$ (2012), estimou-se que a produção média de carne, entre 2007 e 2011, a partir do gado da Amazônia Legal fica em torno de 30\% do total produzido no Brasil (em 2011, 17,8\% da produção nacional de carne foi exportada e $82,7 \%$ foi consumida internamente). Os estados com maior participação na produção de carne bovina na Amazônia são: o Mato Grosso (31\%); Pará (22\%); Rondônia (18\%) e Tocantins $(12 \%)^{7}$.

A política governamental de estímulo a esta produção foi acompanhada não apenas da expansão do rebanho, mas, também da área aberta para pastagens e da própria degradação ambiental. É notório afirmar que o aumento do rebanho está diretamente associado à degradação da floresta amazônica. Dentro dessa lógica, a atividade tornou-se um dos principais condutores do desmatamento e conversor de florestas em pastos, tornando-se a forma predominante de desmatamento na Amazônia (RIVERO et al., 2009).

Além dos efeitos diretos e indiretos da atividade pecuária sobre o desmatamento, outros fatores são sustentados por Fearnside (2006), como a lógica de desmatar para manter a posse da terra e defendê-la de posseiros ou da expropriação do governo (como terra devoluta); as formas de desmatamento que servem para fins de lavagem de dinheiro, particularmente quando os fundos são derivados de fontes ilegais, como tráfico de drogas, corrupção, venda de áreas roubadas ou evasão de impostos; e a perda da cobertura vegetal "oficial" induzida pelo governo, como é o caso das inundações causadas pelas barragens hidroelétricas.

Atualmente, a pecuária faz parte da paisagem tanto nas áreas de colonização recente quanto nas mais antigas configurando-se como o uso da terra preferido entre pequenos agricultores e grandes proprietários (UHL et al., 1997). Estudos revelam que, o rebanho cresceu $11 \%$ anualmente desde 1997, atingindo o número de 33 milhões em 2004, esse crescimento é apontado como causa do aumento do desmatamento observado nos anos de 2002, 2003 e 2004. Isso se deve a fenômenos como o progresso na erradicação da febre aftosa, desvalorização do Real, surgimento da doença da vaca louca na Europa e melhorias no sistema de produção de carne (NEPSTAD et al., 2006).

Em 2012, o efetivo de rebanho bovino presente na Amazônia Legal atingiu 77,6 milhões de cabeças (Gráfico 4) (IBGE, 2013). Em 2011, os maiores rebanhos estavam no Mato Grosso (29,3 milhões de cabeças), Pará (18,3 milhões de cabeças) e Rondônia (12,2 milhões de cabeças). Esses Estados também possuem as maiores rendas brutas da região em 2011, Mato Grosso com R\$3,9 bilhões (31\% da renda total), Para com

\footnotetext{
${ }^{6}$ Anuário da Pecuária Brasileira.

${ }^{7}$ Com base no estudo realizado pelos Amigos da Terra (2013) estima-se que os quatro estados juntos possuem 64 frigoríficos de um total de 243 frigoríficos cadastrados no Brasil inspecionados pelo Sistema de Inspeção Federal (todo produto exportado tem SIF), que são minoria quando comparados ao número de empreendimentos por Sistema de Inspeção Estadual (466) e Sistema de Inspeção Municipal (803). A respeito do abate de carne oficial irregular e clandestino, o estudo concluiu que aproximadamente 10,6 milhões de cabeças de gado bovino são consumidos no Brasil sem inspeção de um total de 30 milhões destinados ao mercado doméstico, ou seja, um terço do total.
} 
R\$ 2,9 bilhões (22\%) e Rondônia com R\$ 2,3 bilhões (18\%) (Tabela 1 e Gráfico 5).

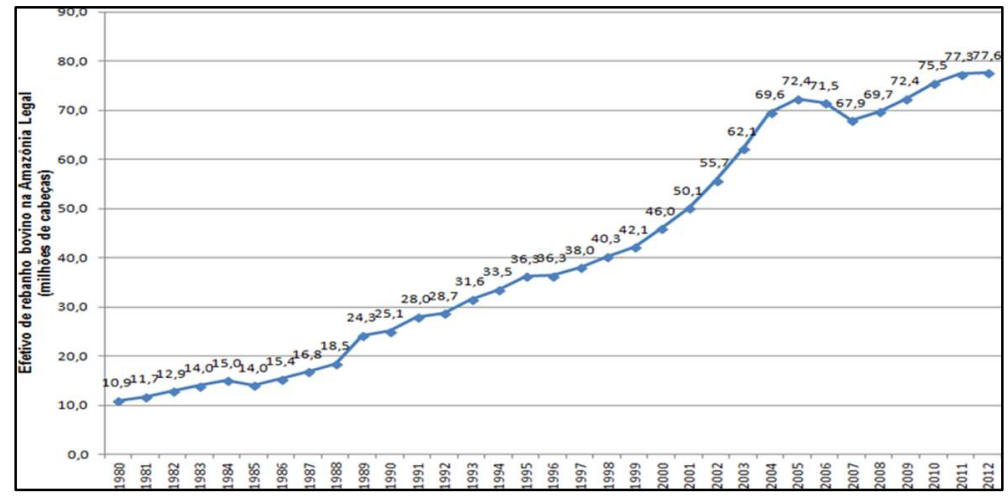

Gráfico 4: Evolução do Efetivo de Rebanho Bovino na Amazônia Legal entre 1980 e 2012. Fonte: IBGE (2013).

Tabela 1: Evolução da Renda Bruta da Pecuária de Corte na Amazônia entre os anos de 2000 e 2011.

\begin{tabular}{|c|c|c|c|c|c|}
\hline \multirow[b]{2}{*}{ Estados } & \multicolumn{5}{|c|}{ Renda bruta da pecuária de corte em milhões de reais } \\
\hline & 2000 & 2004 & 2007 & 2010 & 2011 \\
\hline Rondônia & $1.008,22$ & $1.511,56$ & $1.464,36$ & $2.151,03$ & $2.257,08$ \\
\hline Acre & 179,19 & 203,11 & 208,36 & 326,19 & 430,20 \\
\hline Amazonas & 259,45 & 271,65 & 231,47 & 522,06 & 517,86 \\
\hline Roraima & 80,28 & 78,45 & 68,02 & 132,83 & 137,01 \\
\hline Pará & $1.178,15$ & $1.689,86$ & $1.759,32$ & $2.678,32$ & $2.869,13$ \\
\hline Amapá & 47,73 & 24,00 & 14,34 & 23,59 & 29,91 \\
\hline Tocantins & $1.059,09$ & $1.073,17$ & 907,81 & $1.280,73$ & $1.552,63$ \\
\hline Maranhão & 551,53 & 665,77 & 634,30 & $1.056,65$ & $1.151,93$ \\
\hline Mato Grosso & $3.273,81$ & $3.396,42$ & $2.784,18$ & $3.719,82$ & $3.944,53$ \\
\hline Amazônia Legal & $7.637,45$ & $8.914,00$ & $8.072,16$ & $11.891,22$ & $12.890,28$ \\
\hline
\end{tabular}

Fonte: ANUALPEC/FNP (2012).

${ }^{\mathrm{a}}$ A renda bruta atualizada para valores monetários de 2011 pelo IGP-DI (FGV) é igual a produção de carne bovina (arroba equivalente a carcaça) multiplicada pelo preço médio da arroba de boi gordo cobrado em onze regiões representativas da Amazônia (municípios de Barra do Garça, Cáceres, Cuiabá e Colider no Estado de Mato Grosso; Marabá, Redenção e Paragominas no Pará; Araguaína e Gurupi no Tocantins; Rondônia e Açailândia no Maranhão.

b Foram considerados apenas os municípios do Estado do Maranhão que pertencem a Amazônia Legal.

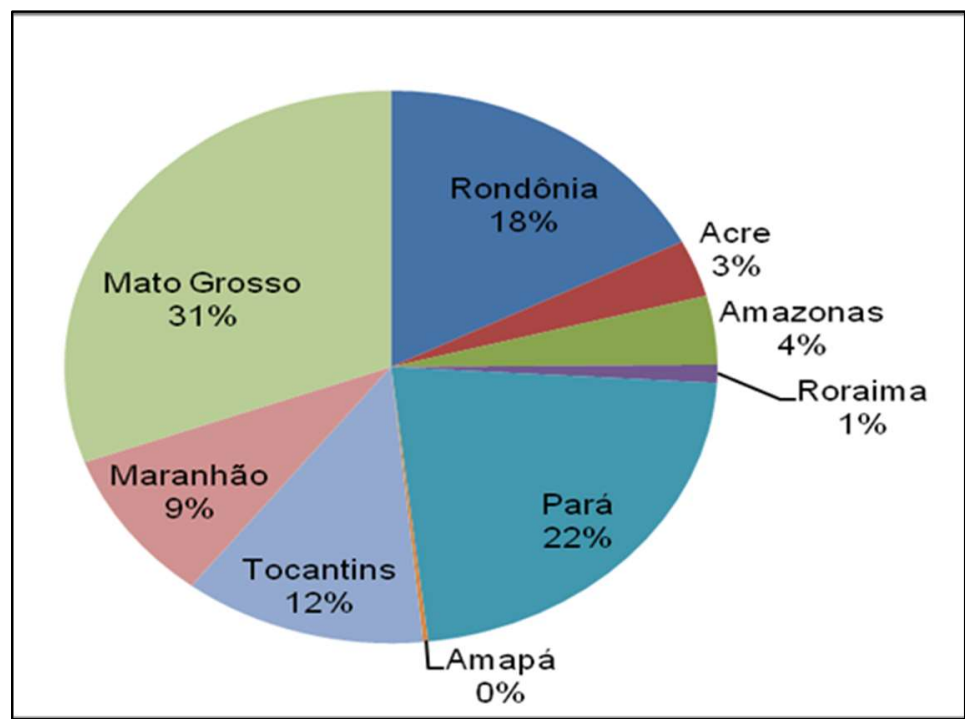

Gráfico 5: Porcentagem de Participação dos Estados da Amazônia na Renda Bruta da Pecuária de Corte em 2011. Fonte: ANUALPEC/FNP (2012).

Apesar de o rebanho bovino ter uma maior importância em termos de efetivo animal na Amazônia, outros rebanhos, como o suíno, o caprino e o ovino, também se destacam. O efetivo de rebanho suíno, entre 
Pagamento por serviços ambientais por desmatamento evitado: proposta de estimação do custo de oportunidade do uso do solo para pecuária no Mato Grosso

ALVES, V. P.; CARVALHO, A. V.; GUIMARÃES, J. L. C.; GALVÃO, J. B. G.; TANAKA FILHO, M.; CARVALHO E. N.; ALMEIDA, R. M.; FEITOSA, J. R. P.

1990 e 2011, apresentou uma queda de 7,8 milhões, em 1990, para 4,8 milhões em 2011, ou seja, houve uma redução de 3 milhões de cabeças. Não obstante, o efetivo de rebanho de caprinos e ovinos vem apresentando um crescimento notável desde 1996 (1 milhão de cabeças), atingindo 1,9 milhões em 2011 (SANTOS et al., 2013).

\section{Discussão sobre REDD+ e pagamento por serviços ambientais}

O mecanismo de redução de emissões provenientes do desmatamento e degradação florestal (REDD) foi um tema que ganhou mais relevância a partir da Conferência das Nações Unidas sobre Mudança Climática (COP 13), realizada em 2007 em Bali. A partir de então, este se tornou o tema central das negociações entre as partes, que chegaram a um acordo REDD+ em 2010 realizado em Cancun (COP 16), onde o REDD passou a envolver a conservação, a administração sustentável de florestas e o aumento do estoque de carbono.

A ideia básica do REDD é recompensar financeiramente os países dispostos e em condições de reduzir as emissões por desmatamento. No Brasil, o Plano Nacional sobre Mudança do Clima, criado em 2008, e a Política Nacional sobre Mudança do Clima (Lei n. 12.187 e Decreto n. 7.390/2010), aprovada em 2009 detalham ações e metas necessárias para cumprir o compromisso voluntário nacional de redução de $36,1 \%$ a $38,9 \%$ das emissões de gases de efeito estufa. Um dos objetivos propostos pelo plano é a redução sustentada das taxas de desmatamento na Amazônia, alcançando o desmatamento ilegal zero, assim como a eliminação da perda líquida de cobertura vegetal. Para o futuro, a meta do governo é reduzir $80 \%$ do desmatamento em relação à média observada do período de 1996 a 2005 até 2020.

A criação de um sistema nacional de REDD+ também deve levar em consideração o marco legal nacional vigente, algumas dessas leis e políticas são imprescindíveis não apenas para a redução do desmatamento, mas também para a promoção do uso sustentável dos recursos naturais na Amazônia. Entre elas estão: o Código Florestal, Lei no 4.771/1965; Terras indígenas, Título III do Estatuto do Índio, Lei no 6.0001/1973 e Art. 231 da Constituição Federal de 1988; Fundo Amazônia, Decreto no 6.527/2008, etc. (PAVAN et al., 2012).

Os estados mais avançados em níveis de regulamentação são Acre, Amazonas e Mato Grosso, com legislações implementadas ou em construção. Os principais instrumentos técnicos previstos nos marcos legais dos estados são: inventários florestais para quantificar o estoque de carbono presente nas florestas; linha de base para REDD+ que visa estabelecer o cenário de referência para as reduções de emissões estaduais, entre outros. Além desses instrumentos, são previstos o uso de ferramentas de valoração de ativos ambientais que servem de incentivo para o uso sustentável de serviços ambientais de modo geral.

A cerca dos instrumentos econômico-financeiros, os recursos do orçamento estadual, acordos bilaterais e a geração de créditos de serviços ambientais/REDD+ são apontados, pela maioria dos estados, como fontes no âmbito do setor público. Além disso, existem outras fontes potenciais como royalties de empreendimentos hidrelétricos, minerários e petrolíferos. Esses incentivos permitiriam a capitação de recursos estaduais e federais ligados à compensação econômica para ações do setor florestal. No que tange 
Pagamento por serviços ambientais por desmatamento evitado: proposta de estimação do custo de oportunidade do uso do solo para pecuária no Mato Grosso

ALVES, V. P.; CARVALHO, A. V.; GUIMARÃES, J. L. C.; GALVÃO, J. B. G.; TANAKA FILHO, M.; CARVALHO E. N.; ALMEIDA, R. M.; FEITOSA, J. R. P.

ao setor privado, a maioria dos estados apontam como instrumentos econômicos para potenciais estratégias de fomento, a geração de créditos de serviços ambientais e o uso de incentivos positivos.

Atualmente, não existe um mercado compensatório para ações de REDD+ no contexto da UNFCCC. No mercado voluntário de carbono, foram desenvolvidas metodologias para projetos ou programas subnacionais por organizações independentes, como Verified Carbon Standard (VCS). Alguns estados amazônicos pretendem participar de um Mercado Brasileiro de Redução de Emissões (MBRE) visando ofertar créditos compensatórios a outros estados brasileiros, como São Paulo e Rio de Janeiro.

Além desses, cogita-se que sistemas estaduais estejam considerando outras opções para o financiamento de suas ações de REDD+ pelo uso de incentivos positivos como tributos e pagamentos por serviços ambientais. Nos estados do Mato Grosso e Rondônia discutem a possibilidade de diminuir a carga tributária de agentes sociais que adotem boas práticas ambientais. Outra iniciativa prevista pelo estado do Amazonas é a desoneração de reserva legal por meio de pagamento por serviços ambientais (PSAs) beneficiando proprietários de terras que apoiem projetos de serviços ambientais.

Os Pagamentos por Serviços Ambientais são mecanismos baseados no mercado que tem por finalidade transformar valores externos e não comercializados em termos de serviços ambientais em incentivos financeiros reais a moradores locais responsáveis pela provisão de tais serviços (WÜNSCHER et al., 2008; ENGEL et al., 2008). Esses mecanismos além de auxiliarem na preservação do meio ambiente contribuem para o desenvolvimento econômico, pois são importantes na geração de renda aos seus beneficiários (FASIABEN et al., 2009).

Primeiramente, sobre a estrutura de negociação por transações voluntárias, o esquema de PSA distingue-se de medidas de comando e controle. Desse modo, se pressupõe que os potenciais provedores dos serviços ambientais tenham reais escolhas sobre o uso da terra (WUNDER, 2005). Do outro lado da negociação, um comprador potencial pode ser qualquer pessoa física ou jurídica que tenha disposição a pagar pelo serviço ambiental. Entre os possíveis pagadores estão às empresas privadas, setor público e Organizações Não-Governamentais - ONGs nacionais e internacionais, entre outros.

Outra forma de distinguir os tipos de compradores é: entre PSA privados, onde há um financiamento direto pelos usuários do serviço e, através de PSA públicos, os quais há como mediador, ou melhor, como comprador o Estado, representando os usuários de serviços ambientais (WUNDER et al., 2001; FARIA, 2013). Um exemplo deste último é o que acontece em Costa Rica, um dos primeiros países a implementar esquemas de PSA, o qual o governo é considerado o comprador principal, mesmo que parte dos recursos venha do exterior. Neste caso, a transação é mediada por um fundo nacional.

Assim, existem duas formas pelas quais moradores locais podem se beneficiar através de esquemas de PSA: (i) mediante a venda de serviços ambientais (benefícios diretos) e (ii) mediante impactos positivos no meio ambiente ou na economia local (benefícios indiretos). Com relação ao segundo critério, o serviço ambiental deve ser bem definido por meio de medidas (estoque de carbono em toneladas) ou cobertura de uso do solo capaz de fornecer aquele serviço (florestas conservadas fornecem água potável). A clareza na 
Pagamento por serviços ambientais por desmatamento evitado: proposta de estimação do custo de oportunidade do uso do solo para pecuária no Mato Grosso

ALVES, V. P.; CARVALHO, A. V.; GUIMARÃES, J. L. C.; GALVÃO, J. B. G.; TANAKA FILHO, M.; CARVALHO E. N.; ALMEIDA, R. M.; FEITOSA, J. R. P.

definição desses objetos de negociação depende do conhecimento firmado em base científica e não em crenças populares a respeito dos mesmos. Dessa maneira, uma fraca sustentação científica em relação aos serviços fornecidos em termos tangíveis torna o esquema de PSA inconsistente, gerando dúvidas por parte dos compradores quanto à racionalidade do sistema, podendo acarretar em abandono dos pagamentos pelos compradores.

Uma discussão a respeito das causas do desmatamento na Amazônia também deve ser abordada em qualquer estudo sobre PSA, pois ela serve de base para justificar a criação dos mesmos. Outro aspecto relevante a se pensar a respeito da eficiência de esquemas de PSA é se esta ação implica em um aumento na provisão de um serviço ambiental em comparação com um cenário hipotético sem o PSA (adicionalidade). A adicionalidade é uma questão que foi muito debatida no que tange aos status de florestas em Mecanismo de Desenvolvimento Limpo (MDL) do Protocolo de Quioto, admitindo-se apenas o reflorestamento e florestamento para a elegibilidade dos créditos de carbono, não incluído florestas protegidas que desapareceriam sem os esquemas de PSA (WUNDER et al., 2001). Nesse sentido, vários estudos vêm demonstrando a efetividade da criação de reservas para a redução de desmatamento quando comparadas a outras áreas, porém a pouca capacidade de monitoramento e enforcement nessas áreas abre espaço para a discussão sobre a viabilidade das estratégias de criação de reservas para a conservação de florestas no longo prazo (NEPSTAD et al., 2009).

Por isso, é fundamental o estudo dos cenários de referência, admitindo as implicações da presença e ausência dos esquemas de PSA na região. Os estudos sobre políticas baseadas em cenários que lidam com incertezas atreladas aos custos, assim como aqueles relativos a impactos sociais e econômicos a partir do gerenciamento de serviços ambientais são fundamentais para orientar melhores políticas ambientais. Esta tarefa torna-se um desafio para os elaboradores de propostas de PSA (WUNDER et al., 2001).

\section{Interpretação teórica do custo social do desmatamento}

A questão ambiental foi tratada originalmente de duas maneiras distintas pela Economia Ambiental Neoclássica: pela economia da poluição e pela economia dos recursos naturais. Os danos ambientais, definidos por esta teoria como externalidades negativas, surgem da dicotomia de custos que faz com que a quantidade efetiva de poluição seja maior que a quantidade socialmente ótima, em que os benefícios líquidos da sociedade são máximos (MORAIS, 2009).

Nesse sentido, o valor econômico dos recursos ambientais geralmente não é observável no mercado via sistema de preços capaz de refletir seu custo de oportunidade. Isso acontece por que a maioria dos ativos ambientais não tem substitutos e a inexistência de sinalização de "preços" para seus serviços distorce a percepção dos agentes econômicos, induzindo as falhas de mercado que prejudicam a alocação eficiente desses recursos, evidenciando uma "divergência entre os custos privados e sociais" (PEARCE, 1976; MARQUES et al., 1995; KHAN, 2005).

No entanto, os recursos ambientais têm atributos de consumo associados ao seu uso e à sua 
Pagamento por serviços ambientais por desmatamento evitado: proposta de estimação do custo de oportunidade do uso do solo para pecuária no Mato Grosso

ALVES, V. P.; CARVALHO, A. V.; GUIMARÃES, J. L. C.; GALVÃO, J. B. G.; TANAKA FILHO, M.; CARVALHO E. N.; ALMEIDA, R. M.; FEITOSA, J. R. P.

existência que afetam tanto a produção de bens e serviços privados como diretamente o consumo dos indivíduos. Desse modo, é comum na literatura a desagregação do valor econômico total do recurso ambiental (VET) em valores de uso (VU) e de não-uso (VNU).

O valor de uso pode ser por sua vez, desagregado em: valor de uso direto (VUD), quando se utiliza atualmente um recurso, por exemplo, na forma de extração, visitação ou outra atividade de produção ou consumo direto; valor de uso indireto (VUI), quando o benefício atual do recurso se deriva indiretamente das funções ecossistêmicas e; valor de opção (VO), valor de usos diretos e indiretos que poderão potencialmente existir em futuro próximo. O valor de não-uso (ou valor passivo) representa o valor de existência (VE), dissociado do uso (embora represente consumo ambiental), eles vêm de uma posição moral, cultural, ética ou altruísta relacionado aos direitos de existência de espécies não-humanas ou preservação de outras riquezas naturais, independente de uso atual ou futuro para o indivíduo. Assim, uma expressão para o valor econômico total (VET) seria a seguinte:

$$
V E T=(V U D+V U I+V O)+V E
$$

Com base nessa interpretação, como chama atenção Pearce (1998), danos ambientais a exemplo do desmatamento existe a combinação de três "falhas econômicas": falha de intervenção do governo, falha no mercado local e falha no mercado global. Por esta ótica, entende-se que a alta rentabilidade da atividade produtiva local está diretamente ligada à abertura de estradas, visto que, estas viabilizam a exploração de novas terras, diminuindo os custos de conversão de florestas para outros usos, por exemplo, para expansão da fronteira agrícola. Evidentemente, se estas atividades não fossem rentáveis (do ponto de vista privado) as rodovias construídas não levariam ao aumento do desmatamento. Portanto, como conclui Ferreira et al.2005, se a existência de áreas protegidas funciona como um fator inibidor do desmatamento, a proximidade com as estradas tem uma relação direta como o mesmo.

Nesse sentido, é correto afirmar que, apesar da infraestrutura rodoviária, além de outros subsídios ou créditos do governo, tornar as atividades mais lucrativas elas exercem uma pressão ainda maior sobre a perda de florestas, significando custos ambientais, medidos local, nacional e global, tão altos que os benefícios marginais privados não os compensam, implicando em perdas de bem-estar social as pessoas de forma geral. Assim, apesar dos custos sociais do desmatamento envolver graus de incertezas em função da dificuldade de mensuração dos dados, há inúmeras perdas em termos dos chamados "serviços ambientais", tais como: expansão de terras sujeita à desertificação, destruição da biodiversidade - o valor de existência da perda irrecuperável de espécies animais e vegetais e o sequestro de carbono.

As preferências por benefícios ou por evitar perdas são baseadas nos valores que os consumidores atribuem aos bens. A máxima disposição a pagar (DAP) pode ser considerada uma expressão desses valores. Assim como, a mínima disposição a aceitar (DAA) é a quantia de dinheiro necessária para compensar um indivíduo pela renúncia de um benefício ou por um custo sofrido, e está reflete o valor de tal benefício ou perda (MARKANDYA et al., 2002).

\section{Metodologia de estimação do custo de oportunidade do desmatamento}


A rentabilidade corrente da pecuária bovina é calculada através dos fluxos monetários resultantes da venda da produção pecuária menos os custos de produção, além da rentabilidade de capital baseada no preço da terra do tipo pastagem. As receitas e custos da pecuária de corte foram obtidos através dos dados publicados no Anuário Estatístico da Pecuária (ANUALPEC, 2004 - 2012) para os anos entre 2003 a 2011. Primeiramente, a receita bruta de produção da pecuária de corte foi calculada a partir da multiplicação das toneladas equivalente a carcaça pelo preço médio de venda do boi em reais por toneladas referentes aos municípios: Barra do Garças, Cáceres, Cuiabá e Colider, do estado do Mato Grosso.

Os custos de produção são referentes aos sistemas de criação extensivo, intensivo e semi-intensivo de gado da raça nelore. De posse dos dados, se obteve a receita líquida por hectare, considerando o total de áreas de pastagem segundo a classificação de uso do solo definida pelo INPE (2013), somando o valor estimado do preço do hectare de pastagem. A tabela 2 a seguir demonstra o resultado das estimativas.

Tabela 2: Estimativa da receita da pecuária no Estado do Mato Grosso (2003 - 2011).

\begin{tabular}{|c|c|c|c|c|c|c|c|c|c|}
\hline \multirow[b]{2}{*}{ Item } & \multicolumn{9}{|c|}{ Estimativa da Receita da Pecuária (R\$/há) entre 2003 e 2011} \\
\hline & 2003 & 2004 & 2005 & 2006 & 2007 & 2008 & 2009 & 2010 & 2011 \\
\hline $\begin{array}{l}\text { Receita } \\
\text { Líquida }\end{array}$ & 2,09 & 1,63 & 1,20 & 1,05 & 0,78 & 2,56 & 1,36 & 1,61 & 1,89 \\
\hline $\begin{array}{l}\text { Preço } \\
\text { terra } \\
\end{array}$ & $\mathrm{da} 2.246,77$ & $2.152,39$ & $1.803,56$ & $1.727,63$ & $1.947,40$ & $1.878,96$ & $2.059,85$ & $2.010,44$ & $2.555,92$ \\
\hline Total & $2.248,86$ & $2.154,02$ & $1.804,76$ & $1.728,68$ & $1.948,18$ & $1.881,52$ & $2.061,22$ & $2.012,05$ & $2.557,81$ \\
\hline
\end{tabular}

Para o cálculo do valor potencial monetário do sequestro de carbono, primeiramente, estimou-se o estoque líquido da biomassa de carbono para o estado do Mato Grosso baseado no estudo de Saatchi et al. (2007), levando em conta as emissões de CO2 entre os anos 2003 e 2011 (INPE, 2013), por último, multiplicou-se esses ao preço pago pela tonelada de carbono no mesmo período no mercado da Chicago Climate Exchange - CCX (Bolsa do Clima de Chicago). As estimativas dos custos incorridos por demandantes de crédito de carbono em termos do estoque líquido ${ }^{88}$ de $\mathrm{CO} 2$ estimado para o estado do Mato Grosso estão reunidos na tabela 3 a seguir.

Tabela 3: Estimativa do custo do carbono para o Estado do Mato Grosso (2003 - 2011).

\begin{tabular}{|c|c|c|c|c|c|c|c|c|c|}
\hline \multirow[t]{2}{*}{ Estimativas de estoque Líquido de CO2 (t/há) } & \multicolumn{9}{|c|}{ Custo do Carbono (R\$/tCO2/ha) } \\
\hline & 2003 & 2004 & 2005 & 2006 & 2007 & 2008 & 2009 & 2010 & 2011 \\
\hline 549,47 & $2.653,95$ & $3.956,20$ & $3.230,90$ & $6.346,41$ & $2.439,66$ & $2.280,31$ & 181,33 & 49,45 & 43,96 \\
\hline 732,97 & $3.540,26$ & $5.277,40$ & $4.309,88$ & $8.465,83$ & $3.254,40$ & $3.041,84$ & 241,88 & 65,97 & 58,64 \\
\hline 916,47 & $4.426,56$ & $6.598,60$ & $5.388,86$ & $10.585,26$ & $4.069,14$ & $3.803,36$ & 302,44 & 82,48 & 73,32 \\
\hline
\end{tabular}

A pesquisa fez o levantamento dos dados entre os anos 2003 e 2011 e verificou que a partir de 2008 o preço pago pelo crédito de carbono na Bolsa do Clima de Chicago diminuiu de R\$ 4,15/tCO2 para R\$ 0,08. Essa queda nos preços pode ser explicada pela crise financeira internacional e pela expectativa de inclusão de projetos de REDD no mercado regulatório (PEREIRA et al., 2010).

\footnotetext{
${ }^{8}$ Os valores dos estoques líquidos de $\mathrm{CO} 2$ foram calculados a partir das estimativas da biomassa em tC com base no estudo realizado por Saatchi et al. (2007), as quais foram subtraídas de 0,28 tC (BUSTAMANTE et al., 2012) multiplicadas por um fator de conversão de 3,67 tCO2 (BANCO MUNDIAL, 2011), transformando o valor da biomassa em CO2.
} 
Pagamento por serviços ambientais por desmatamento evitado: proposta de estimação do custo de oportunidade do uso do solo para pecuária no Mato Grosso

ALVES, V. P.; CARVALHO, A. V.; GUIMARÃES, J. L. C.; GALVÃO, J. B. G.; TANAKA FILHO, M.; CARVALHO E. N.; ALMEIDA, R. M.; FEITOSA, J. R. P.

Em contrapartida, a rentabilidade da pecuária mostrou-se superior ao custo do carbono calculado a partir de 2009. De acordo com a série histórica, a rentabilidade da pecuária estimada aumentou de $\mathrm{R} \$ 1,8$ mil/há em 2008 para R\$ 2,5 mil em 2011. Enquanto que o custo do carbono estimado, considerando o estoque líquido de 150tC/há, reduziu de R\$ 2,2/ha em 2008 para cerca de R\$ 43/há em 2011.

No que tange apenas a receita líquida média de venda da pecuária, sem levar em conta a apreciação da terra, entre 2003-2011 foi igual a $R \$ 1,5 /$ há, o que sugere que o custo de oportunidade do desmatamento devido ao uso do solo para a atividade produtiva é bem pequeno se comparado ao benefício monetário do estoque de carbono com a criação de programas de PSAs.

Por fim, após a mensuração dos valores calculou-se o Valor Presente Líquido (VPL) a fim de se avaliar os mesmos em um horizonte de tempo de 40 anos a uma taxa de desconto social de $2 \%$ a.a., considerando a taxa de crescimento do consumo per capita mundial nos anos 2000 segundo estudo realizado pela Food and Agriculture Organization of the United Nations (FAO, 2011). A escolha para esta taxa fundamenta-se no padrão de fórmula para o desconto do consumo futuro igual a:

$$
d=\sigma+\mu g
$$

Onde: $\boldsymbol{d}$ é a taxa de desconto social; $\boldsymbol{\sigma}$ é a taxa de preferência temporal pura; $\boldsymbol{\mu}$ é a elasticidade da função utilidade de consumo marginal e; $g$ é a taxa de crescimento do consumo per capita.

Dessa forma, se a função utilidade é logarítmica, logo $\mu=1$. Além disso, assume-se que a taxa de preferência tende a zero quando a sociedade prioriza o consumo das gerações futuras, então d=g. Assim, a taxa de desconto será igual a taxa de crescimento do consumo per capita (TURNER, 1993). Dessa forma, sociedades que se importam mais com o crescimento do consumo atual imporão valores maiores para a taxa de desconto, enquanto as economias preocupadas em investir hoje para maior consumo no futuro tendem a impor valores menores para esta taxa (MARGULIS, 1990).

As estimativas se limitaram a algumas parcelas de valor para as quais foi possível a quantificação monetária com base nos preços praticados via mercado. Com base nisso, assume-se que as rendas provenientes da atividade produtiva estão associadas à derrubada da floresta, uma vez que está é apontada pela literatura como propulsora da externalidade ambiental mais devastadora na região que é o desmatamento. Em contrapartida, o preço potencial pago pelo crédito de carbono estimado, admitindo o estoque líquido de carbono presente na região, está associada à preservação da floresta em caso de implementação de programas de PSAs.

Nesse sentido, as parcelas estimadas foram relativas ao valor de uso direto (VUD) associado ao uso do solo como pastagem para a atividade pecuária que em termos de valor presente líquido (VPL) somam R\$ 103,7 mil, enquanto que o valor de uso indireto (VUI) associado à função ecossistêmica da floresta como reservatório de carbono somam $\mathrm{R} \$ 1,8 \mathrm{mil} ; \mathrm{R} \$ 2,4$ mil e $\mathrm{R} \$ 2,9 \mathrm{mil}$, respectivamente com base nas estimativas do estoque líquido de carbono (549,47; 732,97 e 916,47 tC/há).

O valor presente líquido corresponde ao somatório dos fluxos de rendimentos esperados para cada período ( $n=1,2, \ldots, 29$ ), trazidos para valores do período zero, por uma taxa de desconto equivalente a taxa $2 \%$, somado aos valores estimados (rentabilidade da pecuária e custo do carbono) tomando o ano de 2011 
Pagamento por serviços ambientais por desmatamento evitado: proposta de estimação do custo de oportunidade do uso do solo para pecuária no Mato Grosso

ALVES, V. P.; CARVALHO, A. V.; GUIMARÃES, J. L. C.; GALVÃO, J. B. G.; TANAKA FILHO, M.; CARVALHO E. N.; ALMEIDA, R. M.; FEITOSA, J. R. P.

como o inicial e o ano 2040 como o final.

\section{CONCLUSÕES}

A máxima disposição a pagar e a mínima disposição a aceitar indicam em termos monetárias as mudanças de bem-estar sofridas pelos consumidores dado o trade-off entre atividades tradicionais de uso do solo que implicam em desmatamento e atividades alternativas de baixo impacto ambiental. Com base nisso é correto afirmar que a máxima disposição a pagar (DAP) pelo dano causado pelo desmatamento é pelo menos igual ao valor de uso direto (VUD) estimado para o uso da terra para a pecuária, e a mínima disposição a aceitar (DAC) como compensação pelo dano sofrido é no máximo igual ao valor de uso indireto (VUI) estimado para preço do estoque de carbono. Dito de outra forma, pelo princípio de custo de oportunidade, assume-se a hipótese de que alternativas de preservação ambiental geram benefícios que são pelo menos iguais aos benefícios renunciados.

De acordo com esta teoria, em linhas gerais, através dos resultados alcançados com a pesquisa, podese concluir que a compensação financeira através da criação de esquemas de PSAs no estado do Mato Grosso são altamente competitivos para altos índices de preços pagos pela tCO2 comercializados internacionalmente para fins de mitigação do desmatamento provocado, sobretudo, por atividades tradicionais de uso do solo na região de estudo. Os valores monetários estimados sugerem que reduções nas taxas de desmatamento/emissões de CO2 na Amazônia representariam uma oportunidade de ganhos de bem-estar que compensariam o custo de oportunidade do desmatamento em virtude do atual modelo de dinâmica econômica, o qual acaba por se traduzir em perdas de bens e serviços providos pela floresta, entre eles o serviço de sequestro de carbono.

\section{REFERÊNCIAS}

ANUALPEC. Informa Economics South America. Anuário da pecuária brasileira. São Paulo: Informa Economics FNP SOUTH AMERICA, 2012.

BANCO MUNDIAL. Estimating the Opportunity Costs of REDD+. Washington: World Bank Institute, 2011.

BARRETO, P.; PEREIRA, R.; ARIMA, E.. A pecuária e o desmatamento na Amazônia na era das mudanças climáticas. Belém: Imazon, 2008.

BARRETO, P.; SOUZA JUNIOR, C.; NOGUERÓN, R.; ANDERSON, A.; SALOMÃO, R.. Pressão humana na floresta amazônica brasileira. Belém: Imazon, 2005.

BUSTAMANTE, M. M. C.; NOBRE, C. A.; SMERALDI, R.; AGUIAR, A. P. D.; BARIONI, L. G.; FERREIRA, L. G.; LONGO, K.; MAY, P.; PINTO, A. S.; OMETTO, J. P. H.. Estimating greenhouse gas emissions from cattle raising in Brazil. Climatic Change, v.115, n.3-4, p.559-577, 2012.

CELENTANO, D.; VERÍSSIMO, A.. O avanço da fronteira na Amazônia: do boom ao colapso. Belém: Instituto do Homem e Meio Ambiente da Amazônia, 2007.
ENGEL, S.; PAGIOLA, S.; WUNDER, S.. Designing payments for environmental services in theory and practice: An overview of the issues. Ecological Economics, v.65, n.4, p.663-674, 2008.

FARIA, D. L.. Quanto vale a natureza? O sistema de pagamento por serviços ambientais. Revista de Direito Internacional, v.9, n.3, 2013.

FASIABEN, M. C. R.; ANDRADE, D. C.; REYDON, B. P.; GARCIA, J. R.; ROMEIRO, A. R.. Estimativa de aporte de recursos para um sistema de Pagamento por Serviços Ambientais na floresta Amazônica brasileira. Ambiente \& Sociedade, v.12, n.2, p.223-239, 2009. DOI: https://doi.org/10.1590/S1414753X2009000200002

FEARNSIDE, P. M.. Desmatamento na Amazônia: dinâmica, impactos e controle. Acta Amazônica, v.36, n.3, p.395-400, 2006.

FERREIRA, L. V.; VENTICINQUE, E.; ALMEIDA, S.. O desmatamento na Amazônia e a importância das áreas protegidas. Estudos Avançados, v.19, n.53, p.157-166, 2005. 
ALVES, V. P.; CARVALHO, A. V.; GUIMARÃES, J. L. C.; GALVÃO, J. B. G.; TANAKA FILHO, M.; CARVALHO E. N.; ALMEIDA, R. M.; FEITOSA, J. R. P.

FAO. Food and Agriculture Organization of the United Nations. The State of Food and Agriculture. Rome: FAO, 2011.

INPE. Instituto Nacional de Pesquisas Espaciais. Mapeamento da degradação florestal na Amazônia brasileira. Brasília: INPE, 2013.

IBGE. Instituto Brasileiro de Geografia e Estatística. Produção Pecuária Municipal. Brasília: IBGE, 2013.

KHAN, J. R.. The economic approach to environmental and natural resources. 3 ed. Ohio: Thomson South-Western, 2005.

MARGULIS, S.. Causas do Desmatamento da Amazônia Brasileira. Brasília: Banco Mundial, 2003.

MARGULIS, S.. Meio ambiente: aspectos técnicos e econômicos. Rio de Janeiro: IPEA, 1990.

MARKANDYA, A.. Environmental economics for sustainable growth: a handbook for practitioners. London: The World Bank, 2002.

MARIE-GABRIELLE, P.; JONAS, B. V.; JEAN-FRANÇOIS, T.; MARGARIDA, A. A.; RENÉ, P. C.; CORDEIRO, T. M.; NATHALIE, H.; ADRIANO, V.. Por que a pecuária está avançando na Amazônia Oriental?. In: DORIS, S.; JEAN-FRANÇOIS, T.; MARCEL, B.. Amazônia: cenas e cenários. Brasília: Universidade de Brasília, 2004. p.169-189.

MARQUES, G.. Políticas públicas e reconversão da agropecuária paraense. In: CONGRESSO LATINOAMERICANO DE SOCIOLOGIA RURAL, 8. Anais. Porto de Galinhas, 2010. p.1-17.

MARQUES, J. F.; COMUNE, A.. Quanto vale o ambiente: interpretações sobre o valor econômico ambiental. In: ENCONTRO NACIONAL DE ECONOMIA, 23. Anais. 1995. p.633-651.

MORAIS, O. J.. Economia ambiental: instrumentos econômicos para o desenvolvimento sustentável. São Paulo: Centauro, 2009.

NEPSTAD, D. C.; STICKLER, C. M.; ALMEIDA, O. T.. Globalization of the Amazon soy and beef industries: opportunities for conservation. Conservation biology: the journal of the Society for Conservation Biology, v.20, n.6, p.1595-603, 2006.

NEPSTAD, D.; SOARES FILHO, B. S.; MERRY, F.; LIMA, A.; MOUTINHO, P.; CARTER, J.; BOWMAN, M.; CATTANEO, A.; RODRIGUES, H.; SCHWARTZMAN, S.; MCGRATH, D. G.;
STICKLER, C. M.; LUBOWSKI, R.; PIRIS-CABEZAS, P.; RIVERO, S.; ALENCAR, A.; ALMEIDA, O.; STELLA, O.. The end of deforestation in the Brazilian Amazon. Science, n.326, 2009.

PAVAN, M. N.; CENAMO, M. C.. REDD + nos estados da Amazônia: mapeamento de iniciativas e desafios para integração. 2 ed. Ministério do Meio Ambiente, 2012.

PEARCE, D. W.. Economics and environment: essays on ecological economics and sustainable development. Cheltenham: Edward Elgar, 1998.

PEARCE, D. W.. Environmental economics. New York: Longman Icn., 1976.

PEREIRA, D.; SANTOS, D.; VEDOVEDO, M.; GUIMARÃES, J.; VERÍSSIMO, A.. Fatos florestais da Amazônia 2010. Belém: Imazon, 2010.

RIVERO, S.; ALMEIDA, O.; ÁVILA, S.; OLIVEIRA, W.. Pecuária e desmatamento: uma análise das principais causas diretas do desmatamento na Amazônia. Nova Economia, v.19, n.1, p.41-66, 2009.

RIVERO, S.; JAYME JUNIOR, F. G.. A Amazônia do século XXI Belém: EDUFPA, 2008.

SAATCHI, S. S.; HOUGHTON, R. A.; ALVALÁ, R. C. S.; SOARES, J. V.; YU, Y.. Distribution of aboveground live biomass in the Amazon basin. Global Change Biology, v.13, n.4, p.816-837, 2007.

SANTOS, D.; PEREIRA, D.; VERÍSSIMO, A.. O estado da Amazônia: uso da terra. Belém: Imazon, 2013.

SILVA, L. G.. Pecuária e agroindústria de exportação na Amazônia: dinâmicas e perspectivas. Universidade Federal do Pará, 2010.

TURNER, R. K.; PEARCE, D.; BATEMAN, I.. Environmental economics: an elementary introduction. Baltimore: The Johns Hopkins University Press, 1993.

UHL, C.; BEZERRA, O.; MARTINI, A.. Ameaça à biodiversidade na Amazônia Oriental. Belém: Imazon, 1997.

WUNDER, S.. Payments for environmental services: Some nuts and bolts. CIFOR Occasional Paper, n.42, 2005.

WUNDER, S.. Poverty Alleviation and Tropical ForestsĐWhat Scope for Synergies?. World Development, v.29, n.11, 2001.

WÜNSCHER, T.; ENGEL, S.; WUNDER, S.. Spatial targeting of payments for environmental services: $A$ tool for boosting conservation benefits. Ecological Economics, v.65, n.4, p.822-833, 2008.

A CBPC - Companhia Brasileira de Produção Científica (CNPJ: 11.221.422/0001-03) detém os direitos materiais desta publicação. Os direitos referem-se à publicação do trabalho em qualquer parte do mundo, incluindo os direitos às renovações, expansões e disseminações da contribuição, bem como outros direitos subsidiários. Todos os trabalhos publicados eletronicamente poderão posteriormente ser publicados em coletâneas impressas sob coordenação da Sustenere Publishing, da Companhia Brasileira de Produção Científica e seus parceiros autorizados. Os (as) autores (as) posteriormente ser publicados em coletâneas impressas sob coordenação da Sustenere Publishing, da Companhia Brasileira de Produção Cientifica e seus pâ.
preservam os direitos autorais, mas não têm permissão para a publicação da contribuição em outro meio, impresso ou digital, em português ou em tradução. 